\title{
SH-SAW Sensor Based Microfluidic System for the Detection of Heavy Metal Compounds in Liquid Environments
}

\author{
Zeinab Ramshani* ${ }^{1}$, Avuthu S. G. Reddy ${ }^{1}$, Binu B. Narakathu ${ }^{1}$, Jared \\ T. Wabeke ${ }^{2}$, Sherine O. Obare ${ }^{2}$,Massood Z. Atashbar ${ }^{1}$ \\ ${ }^{1}$ Department of Electrical and Computer Engineering \\ ${ }^{2}$ Department of Chemistry \\ Western Michigan University \\ Michigan - 49008, USA
}

*Corresponding author

Email: zeinab.ramshani@,wmich.edu

Address: 4601 Campus Drive, B-236, Western Michigan University,

Department of Electrical and Computer Engineering College of Engineering and Applied Sciences, Parkview Campus,

Kalamazoo, Michigan -49008

Tel: +1 2692764416 


\section{Abstract}

In this work, a guided shear horizontal mode surface acoustic wave (SH-SAW) sensor, fabricated by patterning gold ( $\mathrm{Au}$ ) interdigitated electrodes (IDE) on a $64^{\circ} \mathrm{YX}-\mathrm{LiNbO}_{3}$ based piezoelectric substrate, was used for the detection of heavy metal compounds. A flow cell, with a reservoir volume of $3 \mu 1$, which employs inlet and outlet valves for the microfluidic chamber and polydimethylsiloxane (PDMS) based microfluidic channels, was also designed and fabricated using an acrylic material. The frequency based response of the SAW sensor towards varying concentrations of heavy metal compounds such as lead nitrate $\left(\mathrm{PbNO}_{3}\right)$ and cadmium nitrate $\left(\mathrm{CdNO}_{3}\right)$ were investigated. As the surface acoustic wave propagates on the substrate, between input and output IDEs, a shift in the resonant frequency of the SAW device was observed due to the change in velocity of the wave caused by the varying concentrations of the test analytes. The results obtained demonstrated the capability of the system to detect picomolar level concentrations. The response of the SAW sensor is analyzed and presented in this paper.

Keywords: Heavy metal compounds; Microfluidic; Shear horizontal SAW sensor; Surface acoustic wave device; 


\section{Introduction}

The toxic effects of heavy metals have been a growing concern in the biomedical and environmental industries, and hence a major focus of research in the development of different sensing systems. Although, heavy metals are typically formulated as non-toxic components, it has been shown that they can cause serious health issues even at micro molar concentration levels [1]. Some of the most common heavy metal pollutants are lead $(\mathrm{Pb})$ and cadmium $(\mathrm{Cd})$ [2]. $\mathrm{Pb}$ has been categorized as a neurotoxic element due to its severe impact on the nervous system causing neurotoxicity and nephrotoxicity in the gastrointestinal and renal systems [3-6]. $\mathrm{Cd}$, which has been increasingly used in industrial product lines, is known to cause kidney failure, hypercalciuria and osteoporosis [7-9]. The detection of these heavy metal compounds is thus of utmost importance.

The rising demand for heavy metals in applications such as plating, mining, solar cells, pharmaceutical and chemical industries exacerbate their role in environmental pollution factors $[10,11]$. Heavy metal detection methods including spectrometric techniques such as cold vapor atomic absorption spectroscopy, inductively coupled plasma mass spectroscopy, electrochemical impedance spectroscopy, UV-visible absorbance spectroscopy, x-ray, laser and colorimetric analysis as well as biosensing detection techniques based on enzyme activation or bacteria have been reported [12-19]. However, these techniques are often expensive, time consuming, laborious, hazardous and require complex labeling methods. Therefore, it is necessary to develop sensing systems with easy-to-use, cost effective, highly sensitive and rapid detection techniques.

Surface acoustic wave (SAW) devices have been used in various sensing applications for measuring the changes in SAW device characteristics such as magnitude or phase shift in frequency response [20]. Several advantageous features such as their smaller size, higher 
resonant frequency, lower power consumption and better compatibility with CMOS technology makes them an appropriate choice when compared to micro-cantilever and natural clay-modified electrode based sensing systems [21-24]. Even though different SAW device configurations have been used, since its discovery by Lord Rayleigh in 1885 [25], the use of interdigital electrodes (IDEs) and reflectors by White and Voltmer in 1965 [26] and Staples et al. in 1974 [27], respectively has proven to minimize the power dissipation and hence obtain optimized SAW generation and detection.

SAW devices have been typically used in the Rayleigh and shear horizontal (SH) SAW propagation modes [28]. In the Rayleigh propagation mode, particle displacement has two components: one is parallel to the SAW propagation direction and the other is normal to the substrate, thus forming form an elliptical trajectory for the particle. Most of the SAW energy is confined to the surface of the substrate and is often diminished to zero at a substrate depth of 4 to 5 times the wavelength [29]. Due to the normal component of the particle displacement and interference with other media, above the substrate surface, this mode is not suitable for the liquid environment. On the other hand, in the SH-SAW propagation mode, the particle displacement happens only in parallel with the substrate surface which prevents the vibration vector from transferring into any secondary media and hence prohibits SAW energy attenuation when the substrate comes into contact with a liquid [30]. The use of the SH-SAW device is thus a promising solution for heavy metal compound detection in liquid environments.

In this study, an efficient SH-SAW sensor, consisting of gold (Au) IDEs on a $64^{\circ} \mathrm{YX}$ $\mathrm{LiNbO}_{3}$ based piezoelectric substrate, was fabricated for the detection of heavy metal compounds. A flow cell, which consists of inlet and outlet ports for the microfluidic chamber as well as polydimethylsiloxane (PDMS) based microfluidic channels, was also fabricated using 
acrylic material. A chemical sensing layer, naphtho[2,3-a]dipyrido[3,2-h:2',3'-f]phenazine-5,18dione (QDPPZ) was used to selectively bind to the heavy metal ions. The capability of the system for detecting different concentrations of heavy metal compounds such as lead nitrate $\left(\mathrm{PbNO}_{3}\right)$ and cadmium nitrate $\left(\mathrm{CdNO}_{3}\right)$ in liquid environments, through phase shifts in the frequency based response of the SH-SAW sensor was investigated.

\section{Theory}

The piezoelectric based SH-SAW devices, generally consists of two sets of metalized input and output IDEs mounted on a piezoelectric substrate. The surface acoustic wave is generated by an input electrical signal applied at the input IDEs. It then propagates on the piezoelectric substrate through the delay line which is the distance between the input and output IDEs and is converted back to an electrical signal. The SH-SAW device output signal can finally be obtained from the output IDEs. The SAW resonant frequency can be mathematically calculated by [28]

$$
\begin{aligned}
& f_{0}=\frac{v_{s}}{\lambda} \\
& \lambda=4 \times w
\end{aligned}
$$

where, $f_{0}$ is the resonant frequency of the SAW, $v_{s}$ is the saw propagation velocity on piezoelectric substrate, $\lambda$ is the SAW wavelength and $w$ is the width of the IDEs. The resonant frequency of the SH-SAW sensor is dependent on the velocity of the acoustic wave passing through the piezoelectric substrate. The velocity of the wave is known to vary due to mass, stiffness, conductivity, dielectric coefficient, temperature and pressure changes [31]. The varying concentrations of the heavy metal compounds cause a change in the SAW propagation velocity between input and output IDEs, due to the chemical adsorbent (QDPPZ) that was deposited as a 
sensitive layer, and this resulted in a change in the resonant frequency, which can be used to quantify the concentration levels [32].

\section{Experimental}

\subsection{Chemicals and Sample Preparation}

$\mathrm{PbNO}_{3}$ and $\mathrm{CdNO}_{3}$, in crystalline form, were purchased from the Sigma Aldrich Chemical Company. $\mathrm{PbNO}_{3}$ in concentrations of $1 \mathrm{pM}, 100 \mathrm{pM}, 1 \mathrm{nM}, 100 \mathrm{nM}, 1 \mu \mathrm{M}, 50 \mu \mathrm{M}$, $100 \mu \mathrm{M}$ and $750 \mu \mathrm{M}$ and $1 \mathrm{pM}, 100 \mathrm{pM}, 1 \mathrm{nM}, 100 \mathrm{nM}, 1 \mu \mathrm{M}, 50 \mu \mathrm{M}, 100 \mu \mathrm{M}, 250 \mu \mathrm{M}$ and $\mathrm{CdNO}_{3}$ in concentrations of $750 \mu \mathrm{M}$ were prepared by mixing in deionized (DI) water. $\mathrm{PbNO}_{3}$ and $\mathrm{CdNO}_{3}$ are soluble in the DI water and the process will not be affected by $\mathrm{NO}^{3-}$ anions [33].All test analytes were stored at $-20{ }^{\circ} \mathrm{C}$ in $10 \mathrm{ml}$ aliquots before use. Tubing (Inner diameter

- 0.01"; Outer diameter - 0.0625”) and tube connection accessories for sample transfer was purchased from Upchurch Scientific.

\subsection{SH-SAW Sensor Fabrication}

Figure 1(a) illustrates the schematic of the SH-SAW device. The SH-SAW sensor was fabricated on a $64^{\circ} \mathrm{YX}-\mathrm{LiNbO}_{3}$ piezoelectric substrate using photolithography techniques. Eight pairs of input and output IDEs, $0.1 \mu \mathrm{m}$ thick $\mathrm{Au}$, were patterned by metal sputtering technique on the piezoelectric substrate. The electrode aperture was $760 \mu \mathrm{m}$, while electrode width and gap were $10 \mu \mathrm{m}$ thereby resulting in a $40 \mu \mathrm{m}$ acoustic wave length $(\lambda)$. The SH-SAW sensor also consisted of 120 reflectors fabricated on outer side of input and output IDEs with similar dimensions and 20 reflectors in between the IDEs to reduce the scattering losses of surface acoustic waves [34]. Since the SAW propagation velocity on the $64^{\circ} \mathrm{YX}-\mathrm{LiNbO3}$ piezoelectric substrate is $4474 \mathrm{~m} / \mathrm{s}$ and the designed wavelength is $40 \mu \mathrm{m}$, the resultant resonant frequency will be $111.8 \mathrm{MHz}$ [35]. The measured resonant frequency of the fabricated sensor was 
$112 \mathrm{MHz}$. The photograph of the fabricated SH-SAW sensor, with overall device dimensions of $11 \times 12 \mathrm{~mm}^{2}$ is shown in Fig. 1(b).

\subsection{Synthesis of the Chemical Sensing Layer}

The chemical sensing layer QDPPZ was synthesized using a two-step process. In the first step, concentrated sulfuric acid $\left(\mathrm{H}_{2} \mathrm{SO}_{4}, 20 \mathrm{~mL}\right)$ and concentrated nitric acid $\left(\mathrm{HNO}_{3}, 10 \mathrm{~mL}\right)$ were added dropwise to a mixture of 1,10-phenanthroline $(1.00 \mathrm{~g}, 5.56 \mathrm{mmol})$ in the presence of potassium bromide $(\mathrm{KBr})(5.95 \mathrm{~g}, 50 \mathrm{mmol})$ at $0^{\circ} \mathrm{C}$. The solution was refluxed for 2 hours then cooled to room temperature, yielding a black, oily product. The contents of the flask were diluted with $400 \mathrm{~mL}$ deionized water and neutralized with sodium bicarbonate $\left(\mathrm{NaHCO}_{3}\right)$, yielding a clear yellow solution. The product was extracted with methylene chloride and dried over anhydrous magnesium sulfate $\left(\mathrm{MgSO}_{4}\right)$. The solvents were removed using a rotary evaporator, resulting in a yellow solid. The product was purified by recrystallization from methanol. The average yield of the product, 1,10-phenanthroline-5,6-dione was $(1.11 \mathrm{~g}, 5.31 \mathrm{mmol})$ which was

calculated to be $95 \%$. 1H NMR (400 MHz, $\left.\mathrm{CDCl}_{3}, 25 \mathrm{oC}\right) \delta: 9.12-9.10(\mathrm{t}, 2 \mathrm{H}, \mathrm{J}=2.95 \mathrm{~Hz}$ ), 8.51-8.48 (d, 2H, J = 1.83 Hz), 7.60-7.55 (m, 2H, J = 4.71 Hz). 
In the second step, 1,10-phenanthroline-5,6-dione $(0.50 \mathrm{~g}, 2.38 \mathrm{mmol})$ was refluxed in ethanol for $15 \mathrm{~min} .9,10$-diaminoanthroquinone $(0.981 \mathrm{~g}, 2.38 \mathrm{mmol})$ was then added, resulting in a purple solution, and the solution was refluxed for 4 hours. The dark purple product was collected using vacuum filtration, washed with methanol and concentrated in vacuum. The reaction yield was $80 \%$. $1 \mathrm{H}$ NMR (400 MHz, $\mathrm{CDCl} 3,25 \mathrm{oC}): \delta 9.83(\mathrm{~d}, 1 \mathrm{H}), 9.64(\mathrm{~d}, 1 \mathrm{H}), 9.28$ (d, 2H), $8.64(\mathrm{dd}, 2 \mathrm{H}), 8.27$ (q, 2H), $7.82(\mathrm{~m}, 4 \mathrm{H})$. The final structure is shown in Fig. 2.

\subsection{Microfluidic Flow Cell Fabrication}

The flow cell, with overall device dimension of $70 \times 50 \times 52 \mathrm{~mm}(\mathrm{w} / \mathrm{l} / \mathrm{h})$, was designed in AutoCAD ${ }^{\mathrm{TM}}$ and $\mathrm{CNC}$ machined using acrylic material (Fig. 3). A microfluidic flow channel, with dimensions of $710 \times 6800 \times 710 \mu \mathrm{m}(\mathrm{w} / \mathrm{l} / \mathrm{h})$ and a total channel volume of approximately 3.4 $\mu$ l, was also fabricated with PDMS. The flow of the test analyte through the PDMS microfluidic channel was obtained by integrating two sets of inlet and outlet ports in the flow cell. The effective closing of the flow cell, which results in the tight sealing of the PDMS microfluidic flow channel around the sensing area of the SH-SAW sensor, was made possible by the use of an axially magnetized set of neodymium magnets (Diameter - 0.25"; Thickness 0.375”; Magnetic strength - 13,200 Gauss) purchased from K\&J Magnets, Inc.

\subsection{Experiment Setup}

The experiment setup is shown in Fig. 4. The SH-SAW sensor was placed in the sensor groove of the flow cell. Calibration for the wires and probes was done before the measurements. Before use and at the end of each experiment, the sensor was cleaned with acetone, and then blow dried with pressurized air. The measurements were performed at constant room temperature $\left(25^{\circ} \mathrm{C}\right)$, since any changes in the temperature will affect the SAW velocity and attenuation [36]. Initially, a reference signal for deionized (DI) water was obtained. Then, 
varying concentrations of $\mathrm{PbNO}_{3}(1 \mathrm{pM}, 100 \mathrm{pM}, 1 \mathrm{nM}, 100 \mathrm{nM}, 1 \mu \mathrm{M}, 50 \mu \mathrm{M}, 100 \mu \mathrm{M}$ and $750 \mu \mathrm{M})$, and $\mathrm{CdNO}_{3}(1 \mathrm{pM}, 100 \mathrm{pM}, 1 \mathrm{nM}, 100 \mathrm{nM}, 1 \mu \mathrm{M}, 50 \mu \mathrm{M} 100 \mu \mathrm{M}, 250 \mu \mathrm{M}$ and $750 \mu \mathrm{M}$ ) were injected into the flow cell using a KD Scientific (KDS210P) programmable syringe pump, at a flow rate of $50 \mu \mathrm{l} / \mathrm{min}$. An Agilent 4395A network analyzer was used to measure the phase response $\left(\mathrm{S}_{21}\right)$ of the SH-SAW sensor towards the test analytes. System control, data acquisition and post processing of the network analyzer measurements were performed using a LabView ${ }^{\mathrm{TM}}$ based application.

\section{Results and Discussion}

The development of a selective and sensitive chemical sensing layer relied on the deposition of the organic ligand, QDPPZ, which is a 1,10-phenanthroline derivative that consists of nitrogen and oxygen groups that will coordinate to the heavy metal ions. Initial work has demonstrated that the quinolone unit was essential in inducing selectivity towards the heavy metal ions that was not observed if we used 1,10-phenanthroline alone.The binding of QDPPZ to the heavy metal ions causes an increase in mass between the electrodes, thus affecting the surface acoustic wave function. As the ions flow through the sample channels, QDPPZ molecules coordinate with the metal ions, forming a complex and increase the mass of the material between the electrodes.

Figure 5 shows the phase response $\left(\mathrm{S}_{21}\right)$ of the SH-SAW towards different concentrations of $\mathrm{PbNO}_{3}$. It was observed that the resonant frequency of the reference signal established by DI water shifted from 108.564 MHz to $108.551 \mathrm{MHz}, 108.543 \mathrm{MHz}, 108.529 \mathrm{MHz}, 108.508 \mathrm{MHz}$, 108.503 MHz, $108.499 \mathrm{MHz}, 108.494 \mathrm{MHz}$ and $108.479 \mathrm{MHz}$ for the $1 \mathrm{pM}, 100 \mathrm{pM}, 1 \mathrm{nM}$, $100 \mathrm{nM}, 1 \mu \mathrm{M}, 50 \mu \mathrm{M}, 100 \mu \mathrm{M}$ and $750 \mu \mathrm{M}$ concentrations of $\mathrm{PbNO}_{3}$ solution, respectively (Fig. 5(a)). This results in a frequency shift of $13 \mathrm{kHz}, 21 \mathrm{kHz}, 35 \mathrm{kHz}, 56 \mathrm{kHz}, 61 \mathrm{kHz}, 65 \mathrm{kHz}$, 
$70 \mathrm{kHz}$ and $85 \mathrm{kHz}$ along with a percentage change of $0.011 \%, 0.019 \%, 0.032 \%, 0.051 \%$, $0.056 \%, 0.059 \%, 0.064 \%$ and $0.078 \%$ for the $1 \mathrm{pM}, 100 \mathrm{pM}, 1 \mathrm{nM}, 100 \mathrm{nM}, 1 \mu \mathrm{M}, 50 \mu \mathrm{M}$, $100 \mu \mathrm{M}$ and $750 \mu \mathrm{M}$ concentrations of $\mathrm{PbNO}_{3}$ solution, respectively when compared with DI water (Fig. 5(b)). The experiment was repeated seven times using two different fabricated sensors and standard deviation of $3464 \mathrm{~Hz}, 1732 \mathrm{~Hz}, 2081 \mathrm{~Hz}, 6806 \mathrm{~Hz}, 3464 \mathrm{~Hz}, 4582 \mathrm{~Hz}$, $2081 \mathrm{~Hz}$ and $5567 \mathrm{~Hz}$ from the average value of $15 \mathrm{kHz}, 22 \mathrm{kHz}, 33 \mathrm{kHz}, 48 \mathrm{kHz}, 57 \mathrm{kHz}$, $64 \mathrm{kHz}, 69 \mathrm{kHz}$ and $80 \mathrm{kHz}$ were achieved for the $1 \mathrm{pM}, 100 \mathrm{pM}, 1 \mathrm{nM}, 100 \mathrm{nM}, 1 \mu \mathrm{M}, 50 \mu \mathrm{M}$, $100 \mu \mathrm{M}$ and $750 \mu \mathrm{M}$ concentrations of $\mathrm{PbNO}_{3}$ solution, respectively (Fig. 5(b)).

Then, varying concentrations of $\mathrm{CdNO}_{3}$ was injected onto the SH-SAW sensor. It was observed that the resonant frequency of the reference signal established by DI water shifted from 109.290 MHz to $109.100 \mathrm{MHz}, 109.076 \mathrm{MHz}, 108.989 \mathrm{MHz}, 108.979 \mathrm{MHz}, 108.963 \mathrm{MHz}$, 108.948 MHz, $108.944 \mathrm{MHz}, 108.935 \mathrm{MHz}$ and $108.933 \mathrm{MHz}$ for the $1 \mathrm{pM}, 100 \mathrm{pM}, 1 \mathrm{nM}$, $100 \mathrm{nM}, 1 \mu \mathrm{M}, 50 \mu \mathrm{M} 100 \mu \mathrm{M}, 250 \mu \mathrm{M}$ and $750 \mu \mathrm{M}$ concentrations of $\mathrm{CdNO}_{3}$ solution, respectively. The phase response $\left(\mathrm{S}_{21}\right)$ of the SH-SAW sensor demonstrated a frequency shift of $190 \mathrm{kHz}, 214 \mathrm{kHz}, 301 \mathrm{kHz}, 311 \mathrm{kHz}, 327 \mathrm{kHz}, 342 \mathrm{kHz}, 346 \mathrm{kHz}, 355 \mathrm{kHz}$ and $357 \mathrm{kHz}$ along with a percentage change of $0.173 \%, 0.195 \%, 0.275 \%, 0.284 \%, 0.299 \%, 0.312 \%, 0.316 \%$, $0.324 \%$ and $0.326 \%$ for the $1 \mathrm{pM}, 100 \mathrm{pM}, 1 \mathrm{nM}, 100 \mathrm{nM}, 1 \mu \mathrm{M}, 50 \mu \mathrm{M} 100 \mu \mathrm{M}, 250 \mu \mathrm{M}$ and $750 \mu \mathrm{M}$ concentrations of $\mathrm{CdNO}_{3}$ solution, respectively when compared with DI water (Fig. 6). The experiment was repeated eight times using two different fabricated sensors and standard deviation of $4242 \mathrm{~Hz}, 11313 \mathrm{~Hz}, 11313 \mathrm{~Hz}, 15556 \mathrm{~Hz}, 16970 \mathrm{~Hz}, 24748 \mathrm{~Hz}, 15556 \mathrm{~Hz}$, $14849 \mathrm{~Hz}$ and $12727 \mathrm{~Hz}$ were obtained from the average value of $109 \mathrm{kHz}, 129 \mathrm{kHz}, 175 \mathrm{kHz}$, $192 \mathrm{kHz}, 203 \mathrm{kHz}, 217 \mathrm{kHz}, 221 \mathrm{kHz}, 235 \mathrm{kHz}$ and $271 \mathrm{kHz}$ for the $1 \mathrm{pM}, 100 \mathrm{pM}, 1 \mathrm{nM}$, 
$100 \mathrm{nM}, 1 \mu \mathrm{M}, 50 \mu \mathrm{M} 100 \mu \mathrm{M}, 250 \mu \mathrm{M}$ and $750 \mu \mathrm{M}$ concentrations of $\mathrm{CdNO}_{3}$ solution, respectively.

The resonant frequency phase shifts can be attributed to the change in SAW propagation velocity, in the delay line, caused by the varying concentrations of the test analytes These sets of phase responses also displayed detection levels as low as picomolar concentrations and the ability of the SH-SAW sensor to distinguish among a wide range (micro, nano and pico level) of sample concentrations. It is worth noting that the approved toxicity level of $\mathrm{Pb}$ and $\mathrm{Cd}$ according to the United States Food and Drug Administration (USFDA) is $1.25 \mathrm{mM}$ and $207 \mu \mathrm{M}$, respectively [37].

\section{Conclusion}

In this work, a $\mathrm{SH}-\mathrm{SAW}$ sensor was successfully fabricated on a $64^{\circ} \mathrm{YX}-\mathrm{LiNbO}_{3}$ piezoelectric substrate. An efficient flow cell was also designed and fabricated using acrylic material. The flow cell consisted of inlet and outlet ports for the microfluidic chamber and PDMS based microfluidic channels. The feasibility of using the SH-Saw sensor for detecting heavy metal compounds was demonstrated through the quantitative detection of $\mathrm{PbNO}_{3}$ and $\mathrm{CdNO}_{3}$. The resonant frequency of the SH-SAW sensor increased from $108.551 \mathrm{MHz}$ to 108.479 $\mathrm{MHz}$ and $109.100 \mathrm{MHz}$ to $108.933 \mathrm{MHz}$ as the concentration of $\mathrm{PbNO}_{3}$ and $\mathrm{CdNO}_{3}$ were increased from $1 \mathrm{pM}$ to $750 \mu \mathrm{M}$, respectively. The measured phase response $\left(\mathrm{S}_{21}\right)$ of the SH-SAW sensor showed a $13 \mathrm{kHz}$ and $190 \mathrm{kHz}$ frequency shift for the $1 \mathrm{pM}$ concentration of $\mathrm{PbNO}_{3}$ and $\mathrm{CdNO}_{3}$, respectively. The results obtained demonstrated the capability of the SHSAW sensor to detect heavy metal compounds at picomolar concentrations, which are several orders of magnitude lower than the approved USFDA toxicity limits. The ability to integrate the 
SH-SAW sensor into a hand-held and portable detection system as well as research to improve the sensitivity and selectivity of the SH-SAW sensor to a wider variety of bio/chemicals is part of our future work.

\section{Acknowledgement}

This work has been partially supported by the U.S Army Grant No. W911NF-09-C-0135 and Support for Faculty Scholars Award (SFSA). 


\section{References}

[1] F. Riffat, M. Ahmad, Certain antioxidant enzymes of Allium cepa as biomarkers for the detection of toxic heavy metals in wastewater, Sci. Total Environ. 346 (2005) 256-273.

[2] W.H. Schroeder, J. Munthe, Atmospheric mercury: an overview, Atmos. Environ. 32 (1998) 809-822.

[3] E. Paradis, J. DiCecco, The effects of Thimerosal on the central nervous system of the pond snail lymnaea stagnalis, Bioengineering Conf. (2010) 1-2.

[4] Y.N. Zhang, G.X. Sun, P.N. Williams, Q. Huang, Y.G. Zhu, Assessment of the solubility and bioaccessibility of arsenic in realgar wine using a simulated gastrointestinal system, Sci. Total Environ. 409 (2011) 2357-2360.

[5] W. Kinter, J.B. Pritchard, Altered permeability of cell membranes, Compr. Physiol. (2011) $563-576$.

[6] J. García-Lestón, J. Méndez, E. Pásaro, B. Laffon, Genotoxic effects of lead: an updated review, Environ. Int. 36 (2010) 623-636.

[7] R.C. Okocha, O.B. Adedeji, Overview of cadmium toxicity in fish, J Appl Sci Res. 7 (2011) 1195-1207.

[8] R. Wittman, H. Hu, Cadmium exposure and nephropathy in a 28-year-old female metals worker, Environ. Health Perspect. 110 (2002) 1261.

[9] M. Ciarrocca, M.V. Rosati, F. Tomei, A. Pacchiarotti, P. Corbosiero, C.Di Pastena, B. Scala, A. Capozzella, G. Tomei, T. Caciari, Correlation between Cadmium and blood counts in workers exposed to urban stressor, Int. Arch. Occ. Env. Hea. (2013). 
[10] M.D. Archbold, D.P. Halliday, K. Durose, T.P.A Hase, D. Smyth-boyle, K. Govender, Characterization of Thin Film Cadmium Sulfide Grown Using a Modified Chemical Bath Deposition Process, IEEE PVSC. Conf. (2005.) 476-479.

[11] N. Verma, M. Singh, Biosensors for heavy metals, Biometals 18 (2005) 121-129.

[12] D.T. Quang, J.S. Kim, Fluoro-and chromogenic chemodosimeters for heavy metal ion detection in solution and biospecimens, Chem. Rev. 110 (2010) 6280-6301.

[13] L. Borgese, A. Zacco, E. Bontempi, M. Pellegatta, L. Vigna, L. Patrini, L. Riboldi, F. Rubino, L. Depero, Use of total reflection X-ray fluorescence (TXRF) for the evaluation of heavy metal poisoning due to the improper use of a traditional ayurvedic drug, J. Pharm. Biomed. Anal., 52 (2010) 787-790.

[14] Y.L. Hung, T.M. Hsiung, Y.Y. Chen, Y.F. Huang, C.C. Huang, Colorimetric detection of heavy metal ions using label-free gold nanoparticles and alkanethiols, J. Phys. Chem. C 114 (2010) 16329-16334.

[15] M.R. Knecht, M. Sethi, Bio-inspired colorimetric detection of $\mathrm{Hg}^{2+}$ and $\mathrm{Pb}^{2+}$ heavy metal ions using Au nanoparticles, Anal. Bioanal. Chem. 394 (2009) 33-46.

[16] I. Gammoudi, H. Tarbague, A. Othmane, D. Moynet, D. Rebière, R. Kalfat, C. Dejous, Love-wave bacteria-based sensor for the detection of heavy metal toxicity in liquid medium, Biosens. Bioelectron. 26 (2010) 1723-1726.

[17] A. Soldatkin, S. Dzyadevych, Y. Korpan, T. Sergeyeva, V. Arkhypova, O. Biloivan, O. Soldatkin, L. Shkotova, O. Zinchenko, Peshkova, Biosensors: A quarter of a century of R\&D experience, Biopolym. Cell 29 (2013) 188-206.

[18] A. Gerhardt, Monitoring behavioral responses to metals in Gammarus pulex (L.)(Crustacea) with impedance conversion, Environ.Sci. Pollut. R. 2 (1995) 15-23. 
[19] N.P.W. Pieczonka, G. Moula, R.F. Aroca, SERRS for Single-molecule detection of dyelabeled phospholipids in Langmuir-Blodgett monolayers, Langmuir 19 (2009) 1261-1264.

[20] R. Kshetrimayum, R. Yadava, R. Tandon, Mass sensitivity analysis and designing of surface acoustic wave resonators for chemical sensors, Meas. Sci. Technol. 20 (2009) 055201.

[21] P. Gonzalez, M. Rakowski, D. San Segundo, S. Severi, K. De Meyer, A. Witvrouw, CMOSintegrated poly-SiGe piezoresistive pressure sensor, Electron Device Letters, IEEE 33 (2012) 1204-1206.

[22] O. Tigli and M.E. Zaghloul, Temperature Stability Analysis of CMOS-SAW Devices by Embedded Heater Design, IEEE Trans. Device Mat. Rel. 8 (2008) 705-713.

[23] X. Chen, W. Chen, A. Mulchandani, U. Mohideen, Application of Displacement Principle for Detecting Heavy Metal Ions and Edta Using Microcantilevers, Sens. Actuator B-Chem. 161 (2012) 203-208.

[24] A.A. Issa, Y.S. Al-Degs, N.A.A. Al-Rabady, Selective Electrochemical Detection of Toxic Heavy Metals at Ultra Trace Levels using Natural Clay-Modified-Electrode, Eurasian J. Anal. Chem. 4 (2009).

[25] L. Rayleigh, On waves propagating along the plane surface of an elastic solid, proc. London math. soc. 17 (1885) 4-11.

[26] R. White, F. Voltmer, Direct piezoelectric coupling to surface elastic waves, Appl. Phys. Lett. 7 (1965). 314-316.

[27] E. Staples, S. Schoenwald, R. Rosenfield. C. Hartmann, UHF surface acoustic wave resonators, proc. IEEE UFFC (1974) 245-252.

[28] C.K. Campbell, Surface Acoustic Wave Devices for Mobile and Wireless Communications, Elsevier Science (USA), 1998 
[29] Q. Aisha, L. Yeo, J. Friend, Interfacial destabilization and atomization driven by surface acoustic waves, Phys. Fluids 20 (2008) 074103.

[30] Y. Kwon, Y. Roh, Development of SH-SAW sensors for underwater measurement, Ultrasonics 42 (2004) 409-411.

[31] Di. Pietrantonio, F.M. Benetti, D. Cannata, E. Verona, A. Palla-Papavlu, V. Dinca, M. Dinescu, T. Mattle, T. Lippert, Volatile toxic compound detection by surface acoustic wave sensor array coated with chemoselective polymers deposited by laser induced forward transfer, Application to sarin, Sens. Actuator B-Chem. 174 (2012) 158-167.

[32] C. Ho, E. Lindgren, K. Rawlinson, L. McGrath, and J. Wright, Development of a surface acoustic wave sensor for in-situ monitoring of volatile organic compounds, Sensors, 3 (2003) 236-247.

[33] M. Minceva, R. Fajagar, L. Markovska and V. Meshko, Comparative study of Zn2+, Cd2+, and $\mathrm{Pb} 2+$ removal from water solution using natural clinoptilolitic zeolite and commercial granulated activated carbon. Equilibrium of adsorption, Separation Science and Technology, 43 (2008) 2117-2143.

[34] T. Bauer, G. Kovacs, U. Rosler and W. Ruile, Surface acoustic wave arrangement with a junction region between surface acoustic wave structures having a decreasing then increasing finger period, U.S. Patent No. 6,420,946. 16 Jul. 2002.

[35] K. Yamanouchi, K. Abe, K. Shibayama, Propagation and amplification of rayleigh waves and piezoelectric leaky surface waves in the structure of InSb thin films on LiNbO3, IEEE Trans. Sonics Ultrason., 22 (1975), 369-374 
[36] S. J. Martin, G. C. Frye, and S. D. Senturia, Dynamics and response of polymer-coated surface acoustic wave devices: effect of viscoelastic properties and film resonance, Analytical Chemistry, 66 (1994) 2201-2219.

[37] ORA Lab Manual, FDA Office of Regulatory Affairs, Office of Regulatory Science, Document No. IV-14, 1.54 (2013) 11. 


\section{Author Biographies}

Zeinab Ramshani received a B.Sc. degree in electrical and bioelectrical engineering form Azad university science and research branch Tehran, Iran in 2007, a M.Sc. in electrical engineering and control systems from Technical University Tehran, Iran 2009. She is currently a Ph.D. degree student in the Department of Electrical and Computer Engineering at Western Michigan University, USA, since 2012. Her research interests have focused on sensors and surface acoustic wave micro sensors.

Binu Baby Narakathu received the B.E. degree in Electronics and Communication from Visvesvaraya Technological University, Bangalore, India and the M.Sc. degree in Computer Engineering from Western Michigan University, Kalamazoo, USA in 2009. He is currently pursuing Ph.D. in the Department of Electrical and Computer Engineering at Western Michigan University, Kalamazoo, USA. His research interests include all aspects of design, fabrication, and characterization of high performance sensing systems, microfluidic devices, lab-on-a-chip for point-of-care testing (POCT), biosensors, bioelectronics, printed electronic devices and BioMEMS devices for applications in the biomedical, environmental and defense industries.

Avuthu Sai Guruva Reddy received the B.Tech. degree in Electronics and Computer Engineering from Jawaharlal Nehru Technological University, Hyderabad, AP, India and the M.Sc. degree in Electrical Engineering from Western Michigan University, Kalamazoo, USA in 2011. He is currently pursuing the Ph.D. degree in the Department of Electrical and Computer Engineering at Western Michigan University, Kalamazoo, USA. His research interests include design, fabrication, and characterization of printed sensor structures, transistors, microfluidics and lab-on-a-chip sensing systems. 
Dr. Massood Z. Atashbar received the B.Sc. degree in Electrical Engineering from the Isfahan University of Technology, Isfahan, Iran, the M.Sc. degree in Electrical Engineering from the Sharif University of Technology, Tehran, Iran, and the Ph.D. degree from the Department of Communication and Electronic Engineering, Royal Melbourne Institute of Technology University, Melbourne, Australia, in 1998. From 1998 to 1999, he was a Postdoctoral Fellow with the Center for Electronic Engineering and Acoustic Materials, The Pennsylvania State University, University Park. He is currently a Professor with the Electrical and Computer Engineering Department, Western Michigan University, Kalamazoo. His research interests include physical and chemical microsensor development, wireless sensors, and applications of nanotechnology in sensors, digital electronics, and printed electronic devices. He is the author of more than 160 articles in refereed journals and refereed conference proceedings. He is a member of the editorial board and associate editor for the journal of IEEE Sensors. 


\section{Figures Captions}

Fig. 1. (a) Schematic of the SH-SAW device and (b) fabricated SH-SAW sensor.

Fig. 2. Flow cell with the SH-SAW sensor in the sensor groove (Inset: PDMS microfluidic flow channel).

Fig. 3. Structure of QDPPZ.

Fig. 4. Experimental setup.

Fig. 5. (a) SH-SAW sensor phase response $\left(\mathrm{S}_{21}\right)$ towards varying concentrations of $\mathrm{PbNO}_{3}$ and

(b) percentage change in frequency shift of SH-SAW sensor response.

Fig. 6. SH-SAW sensor frequency shift towards varying concentrations $\mathrm{CdNO}_{3}$. 


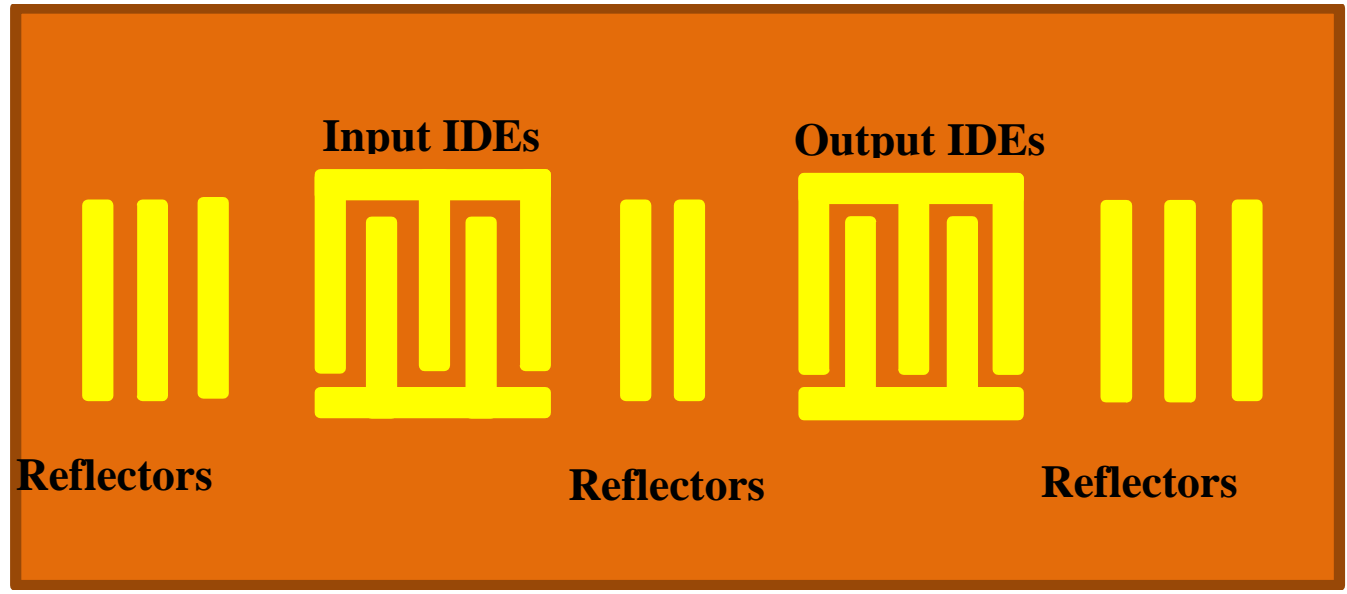

(a)

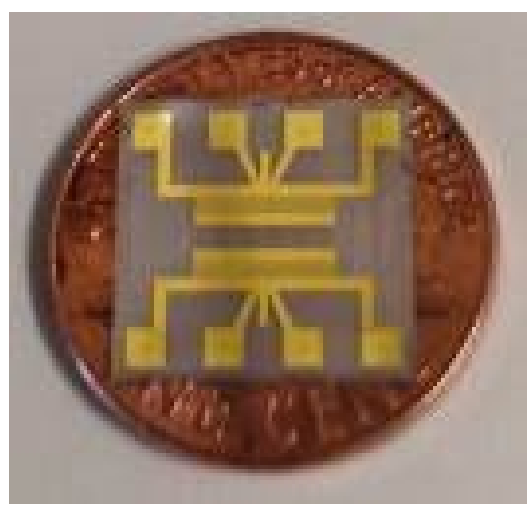

(b)

Figure 1 


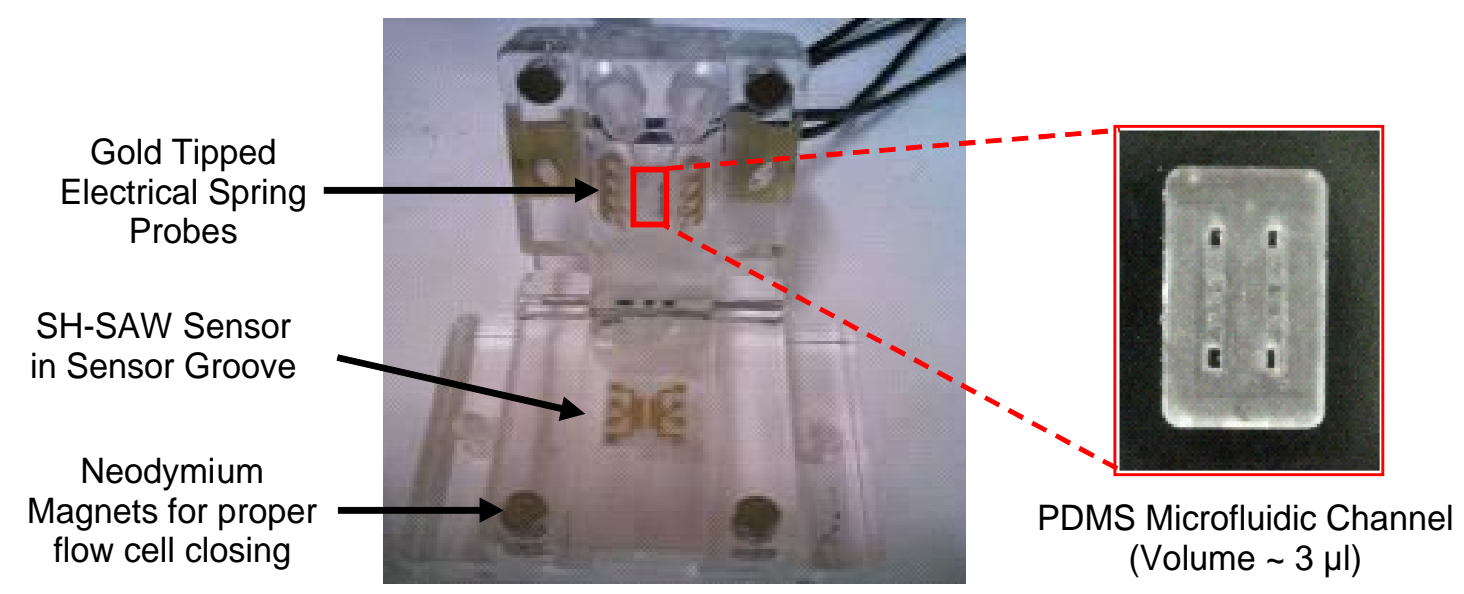

Figure 2 


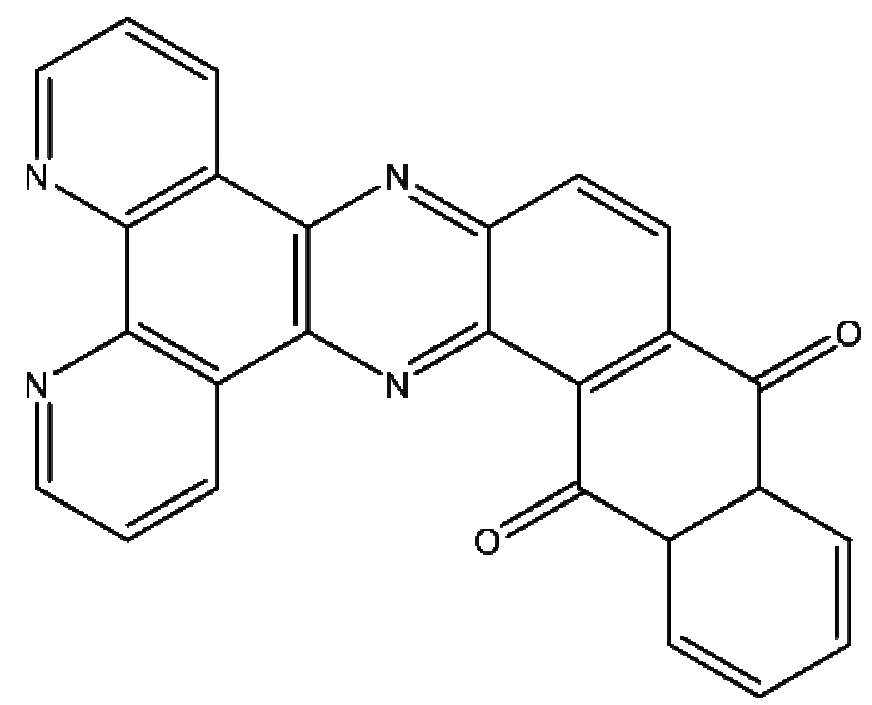

Figure 3 


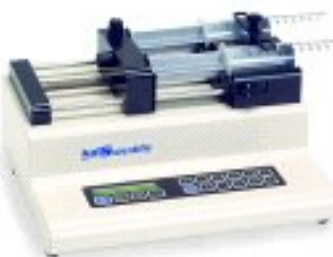

KD Scientific

Programmable Syringe Pump (KDS210P)

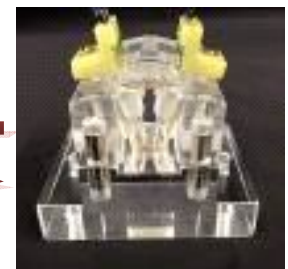

Flow Cell with SH-SAW Sensor

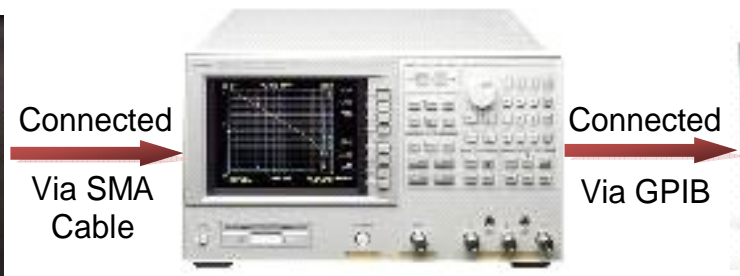

Agilent 4395A

Network Analyzer

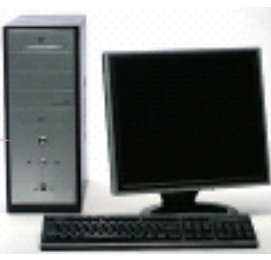

LabView $^{\text {TM }}$

application on PC 

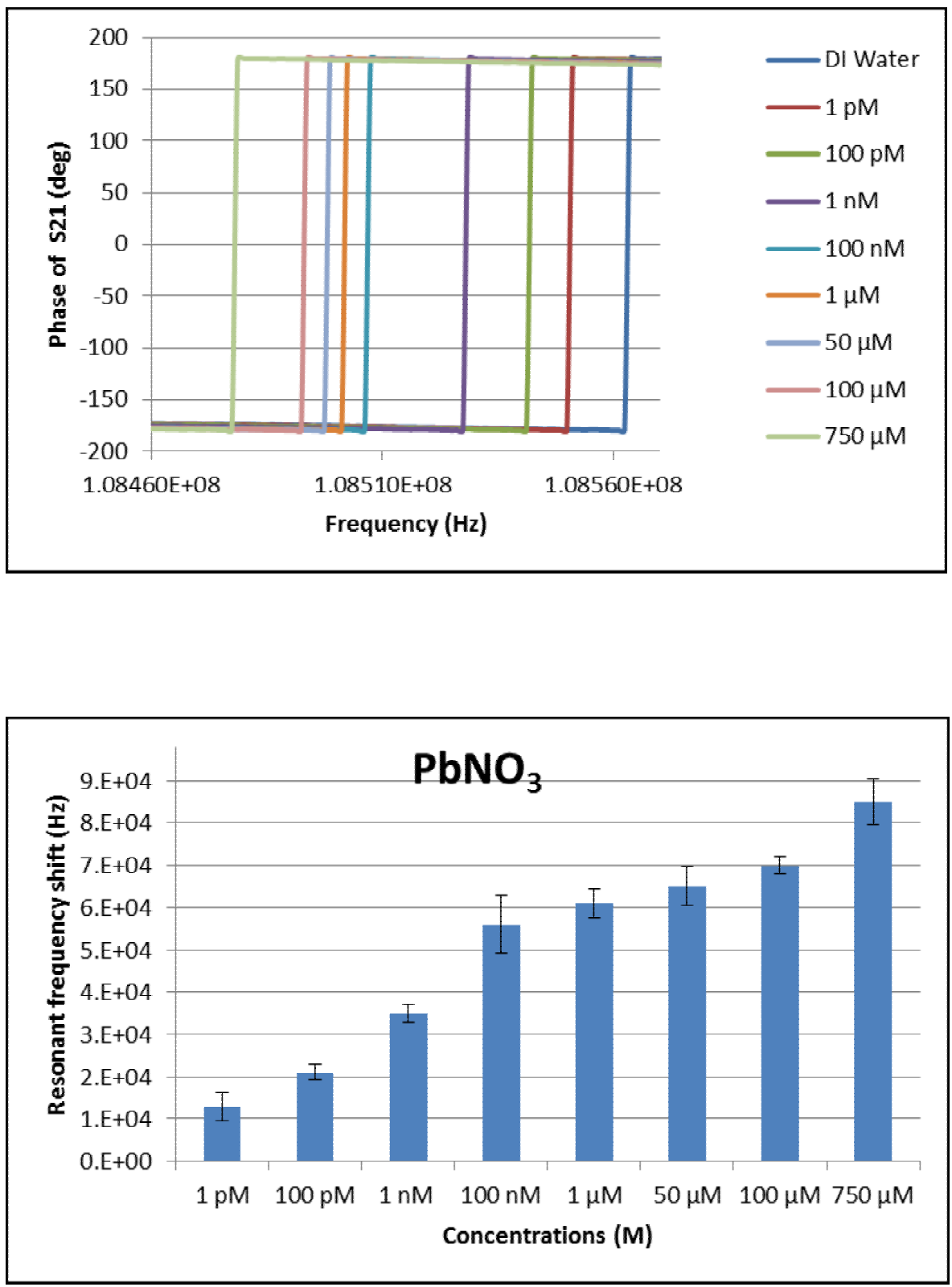

Figure 5 


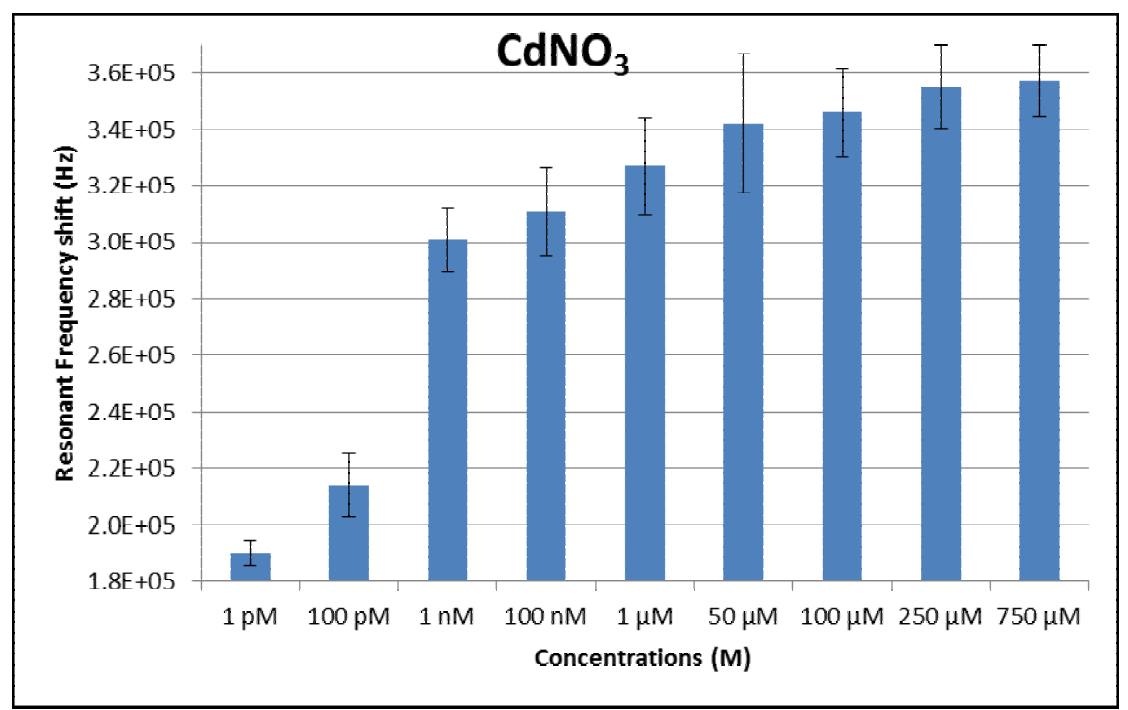

Figure 6 